\title{
Tribological Characteristics of DLC Coatings in Vacuum under Sliding Contact
}

\section{Ananth Kumar, Masahiro Fujii, Takuya Fukuda}

Graduate School of Natural Science and Technology, Okayama University, Okayama, Japan.

Email: clickananth@gmail.com

Received December $12^{\text {th }}, 2011$; revised January $13^{\text {th }}, 2012$; accepted January $20^{\text {th }}, 2012$

\begin{abstract}
Diamond-like Carbon (DLC) coatings of thickness $3 \mu \mathrm{m}$ and $10 \mu \mathrm{m}$ were deposited with and without radical nitriding on stainless steel disk and ring specimens. Plasma CVD method was used to deposit the DLC coatings with silicon as dopant. The specimens were tested in vacuum under sliding contact condition to evaluate the tribological characteristics with reference to the DLC coating thickness and sliding distance. The results revealed that wear resistance was more for the highest coating thickness. The changes on the worn surfaces were observed and wear mechanism is discussed using ex situ analysis.
\end{abstract}

Keywords: DLC; Disk; Ring; Coating Thickness

\section{Introduction}

Modern industries require machine elements of high reliability and longer life. This can be achieved by modifying the surface of the machine elements. Diamond-like Carbon (DLC) coating is extensively used in industries owing to its superior tribological performance [1]. For deposition of DLC coating either a hydrocarbon gas or solid carbon targets can be used. DLC coatings made of hydrocarbon gas contain considerable amount of hydrogen and they are called as hydrogenated DLC coatings, where as the ones made out of solid carbon materials contain no hydrogen or very little and are called as hydrogen free DLCs [2]. The tribological behavior of DLC coatings can be influenced by the deposition process; test conditions, ambient temperature as well as the working environment [3-5]. DLC coatings provide good wear resistant and low friction when applied to mechanical components. DLC coatings in micron level thickness can reduce wear in order of several magnitudes and maintain a low friction in non lubricated condition [6]. The friction and wear of DLC coatings is also affected by the 1) hardness of coating and substrate, 2) thickness of coating, 3 ) roughness of the surface and 4) size and hardness of any debris in the contact [7-9]. The friction and wear mechanism of DLC coatings are complex phenomenon and are controlled by a number of internal and external aspects. The tribological characteristics of DLC coatings are studied widely; however coatings with thickness of 3 $\mu \mathrm{m}$ and above are not investigated much. In this investigation DLC coatings of thickness $3 \mu \mathrm{m}$ and $10 \mu \mathrm{m}$ were developed on disk and ring specimens made of stainless steel. The tribological tests were conducted in vacuum and the tribological behavior is analyzed with respect to the sliding distances and the wear mechanism is also discussed.

\section{Experimental Work}

\subsection{Test Specimen}

Disk and ring specimens were used for evaluating the tribological characteristics in the present study. The specimens were made of martensitic stainless steel (JIS SUS440C). The specimens were quenched and tempered followed by grinding. The arithmetic average roughness of the specimen was $0.3 \mu \mathrm{mRa}$ measured perpendicular to the grinding direction. The Vickers hardness of the specimen surface was around HV (0.3)670. Figure 1 shows the shapes and dimensions of the test specimen.

\subsection{DLC Coating Process}

The surface of both disk and ring part of the specimens were firstly coated with an interlayer of titanium by sputtering to improve adhesion. The a-C:H type DLC coating was deposited on the specimen surfaces by using hot cathode Penning Ionization Gauge (PIG) plasma CVD equipment. $\mathrm{C}_{2} \mathrm{H}_{2}$ gas introduced inside the coating chamber was ionized by plasma and diamond-like carbon was developed on the test specimens in two layers. The ratio of $\mathrm{H} /(\mathrm{C}+\mathrm{H})$ varied from 25 to 35 at $\%$ during the deposition. 

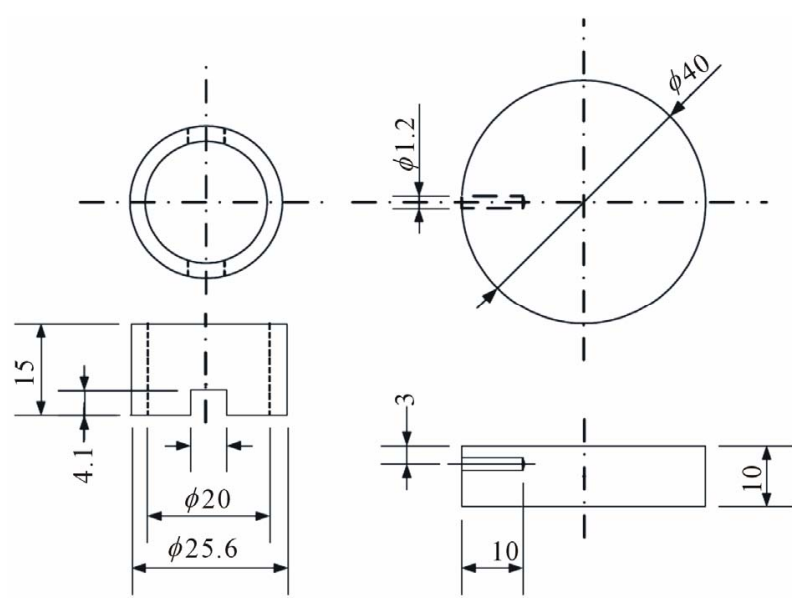

Figure 1. Shape and dimension of specimen.

Silicon was used as dopant in both layers of the DLC coating. In the first layer the dopant decreased gradually during the coating process with the ratio of $\mathrm{Si} /(\mathrm{Si}+\mathrm{C})$ changing from 20 to $10 \mathrm{at} \%$. In the top layer of DLC coating the $\mathrm{Si} /(\mathrm{Si}+\mathrm{C})$ ratio was maintained at 2 at $\%$. The substrate temperature during the coating process remained between 525 and $570 \mathrm{~K}$. Though the coating process temperature was littler higher than the tempering temperature of the specimens, it hardly changed the hardness of substrates as compared to the hardness before deposition of coating. The coating speed of this method was rather high (over $3 \mu \mathrm{m} /$ hour) and the thick coating layer was obtained in comparatively short time. The nominal coating thicknesses were $3 \mu \mathrm{m}$ and $10 \mu \mathrm{m}$. The specimen pretreated with radical nitriding before DLC coating was also used for the study. The surface roughnesses of specimens were increased by the nitriding treatment as well as the DLC coatings process. Table 1 shows the notation and details of DLC coated specimens.

\subsection{Testing Procedure}

The wear test was performed under sliding contact condition in vacuum in the test rig shown in Figure 2 with the detailed view of test chamber. The ring part is fixed to the upper rotating shaft and the disk is placed in the lower section provided with gimbal mechanism. The gimbal mechanism supports a torque arm which measures the frictional force through a load cell. The disk temperature was monitored by thermocouple mounted in the slot of disk and found to be $25^{\circ} \mathrm{C} \pm 1^{\circ} \mathrm{C}$. Vacuum in the order of $10^{-4} \mathrm{~Pa}$ at room temperature could be created with rotary pump and turbo molecular pump. The wear test was performed at room temperature with a sliding velocity of $0.02 \mathrm{~m} / \mathrm{s}$ at a mean surface pressure of 0.5 $\mathrm{MPa}$. The vacuum in the test chamber during the test was in the order of $0.45 \times 10^{-4}-0.55 \times 10^{-4} \mathrm{~Pa}$. The tests
Table 1. Notations and details of specimens.

\begin{tabular}{cccc}
\hline Notation & Pretreatment & $\begin{array}{c}\text { Thickness of } \\
\text { DLC coating }[\mu \mathrm{m}]\end{array}$ & $\begin{array}{c}\text { Average surface } \\
\text { roughness }[\mu \mathrm{mRa}]\end{array}$ \\
\hline D3G & - & 3 & 0.371 \\
D10G & 10 & 0.368 \\
ND3G & Nitriding & 3 & 0.444 \\
ND10G & & 10 & 0.461 \\
\hline
\end{tabular}
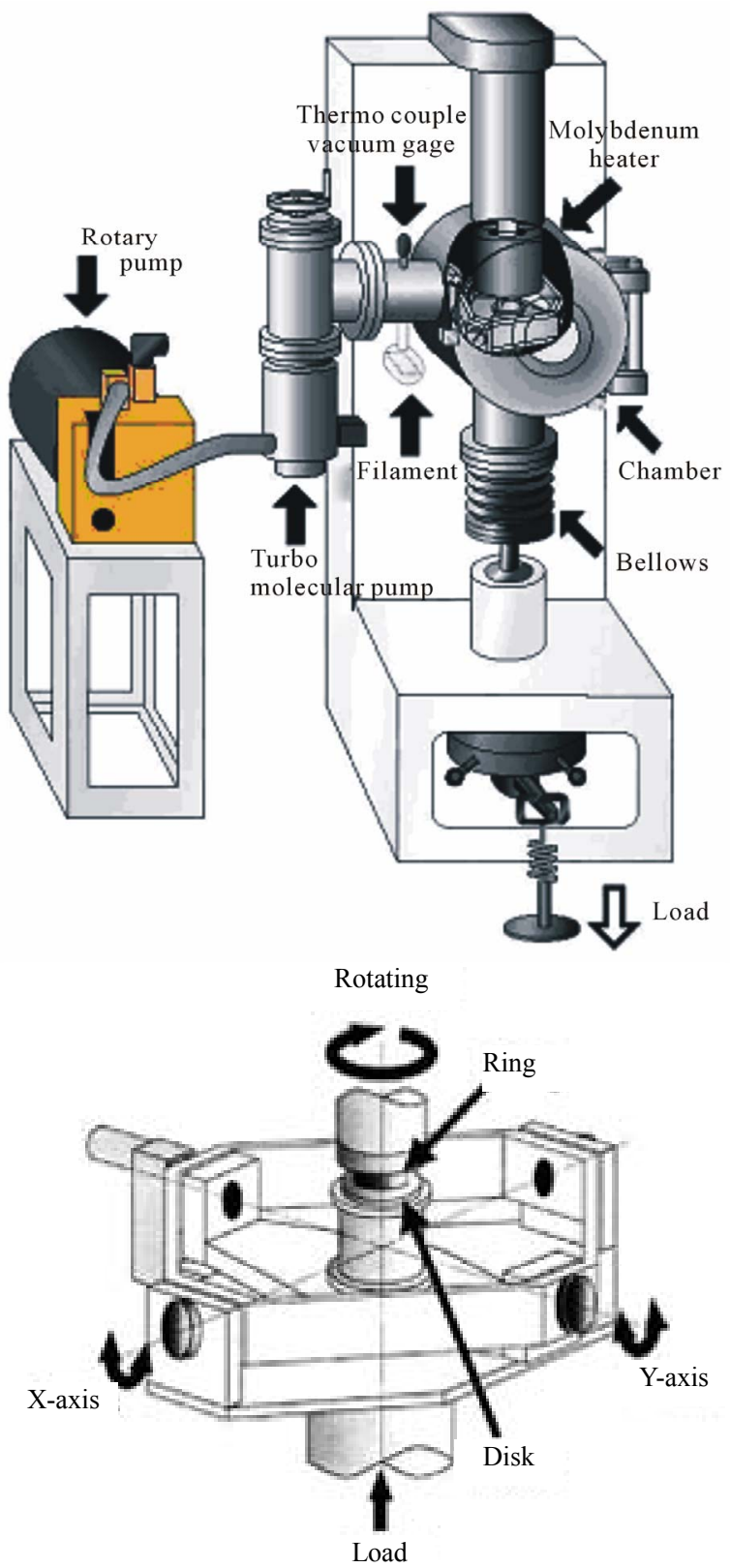

Figure 2. Schematic of disk and ring test rig.

were performed initially for sliding distances of 10, 20, $50,100,200$ and $400 \mathrm{~m}$. Subsequently tests were conducted for sliding distance of $1000 \mathrm{~m}$ each. Between the 
tests; specimens were cleaned with acetone in an ultrasonic bath for 20 minutes and observed under microscope. The surface roughness using profilometer and wear amount by weight loss of both disk and ring were also measured between tests.

\section{Results and Discussions}

\subsection{Friction Coefficient and Wear Behavior}

The friction coefficient and wear characteristic with respect to the sliding distance is shown in the Figure 3. The "arrow mark" in the friction coefficient graph designates the sliding distance at which the failure of specimens was observed. The friction coefficient for the ND3G decreased slightly, as the sliding distance was increased, which may be due to rubbing of wear debris between the sliding parts. The friction coefficient for D3G specimens was equivalent to that of ND3G specimen. The wear amount of D3G and ND3G specimens was same for a sliding distance of $200 \mathrm{~m}$ beyond which increased. However the ND3G specimens showed better wear resistance than the $\mathrm{D} 3 \mathrm{G}$ specimens, which could be due to presence of nitriding layer. The nitriding process improves the surface hardness of substrate and loading carrying capacity which ensures support for the DLC coating. In addition to the improved surface hardness the nitriding process imparts compressive residual stress at the coating/substrate interface. The combination of improved surface hardness and compressive residual stress are likely to provide a uniform strain distribution at the interface and reduces the stress of the coating when loaded, thus extending the durability and wear life [10]. The friction coefficient was same for both D10G and

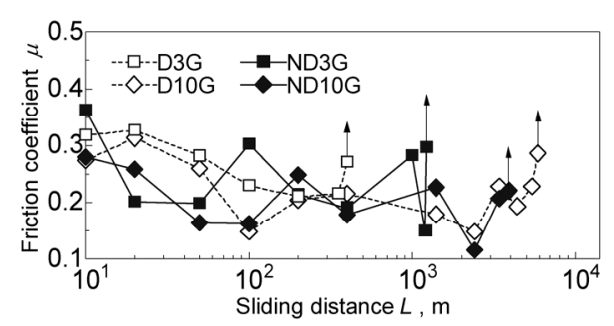

(a)

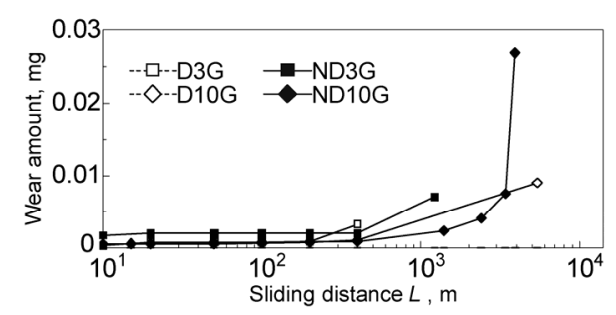

(b)

Figure 3. (a) Change in friction coefficient with sliding distance; (b) Change in wear amount with sliding distance.
ND10G specimens. The value of friction coefficient tends to decrease for the D10G and ND10G specimens due to rubbing of wear particles as the sliding distance increased. The D10G specimens showed marginally better wear resistance than that of ND10G specimens. The ND10G specimens had higher value of surface roughness and large asperities which was due to the nitriding process. These large asperities tend to wear out in bulk during the sliding contact which could have resulted in comparatively large amount of wear in the DLC coatings of ND10G specimens. From the thickness context; D10G and ND10G specimens showed lower friction coefficient values than the $3 \mu \mathrm{m}$ thick DLC coated specimens during the sliding tests. The amount of wear is almost equivalent for $10 \mu \mathrm{m}$ thick DLC coated specimen up to $400 \mathrm{~m}$ of sliding distance after which increased differently for each specimen. As the sliding distance increased the wear amount of DLC coatings was more which may be due to the removal of coatings in the form of wear debris.

\subsection{Surface Analysis of Worn Surfaces}

The surface of the specimens was observed by optical microscope before the test as well as intermittently at specific intervals during the test until the failure of coatings. The surface profile curves of the specimens were also measured during the course of test with a profile meter.

The changes in the surface topography and roughness were examined on both the disk and ring parts. However more changes on the surface were observed on the disk part during the sliding test. Hence the optical micrographs and profile curves of disk part are used for surface analysis of worn surfaces. It is also well documented in the earlier reports that the wear characteristics and wear mechanism are more pronounced and observed on the stationary part during the sliding contact tests $[11,12]$. The surface micrographs and profile curves of D3G specimens were shown in Figure 4. It could be well noticed from the micrographs and profile curves up to $50 \mathrm{~m}$ of sliding the wear process was mild which was evident from the smoothening of asperities. Between 50 to $200 \mathrm{~m}$ of sliding the wear process was gradual which could be noticed from the deepening of profile curve. The complete wear of DLC coating of D3G specimen was observed in the micrograph with the exposure of stainless steel substrate as well as from the profile curve taken after $400 \mathrm{~m}$ of sliding distance. The surface micrographs and profile curves of ND3G specimens were shown in Figure 5. Similar to D3G specimens the ND3G specimens showed mild wear pattern up to $50 \mathrm{~m}$ of sliding distance. Beyond $50 \mathrm{~m}$ the wear process was more pronounced which could be observed from the deepening of profile curves. It could also be noticed that there was gradual wear process. At $1100 \mathrm{~m}$ of sliding distance; 


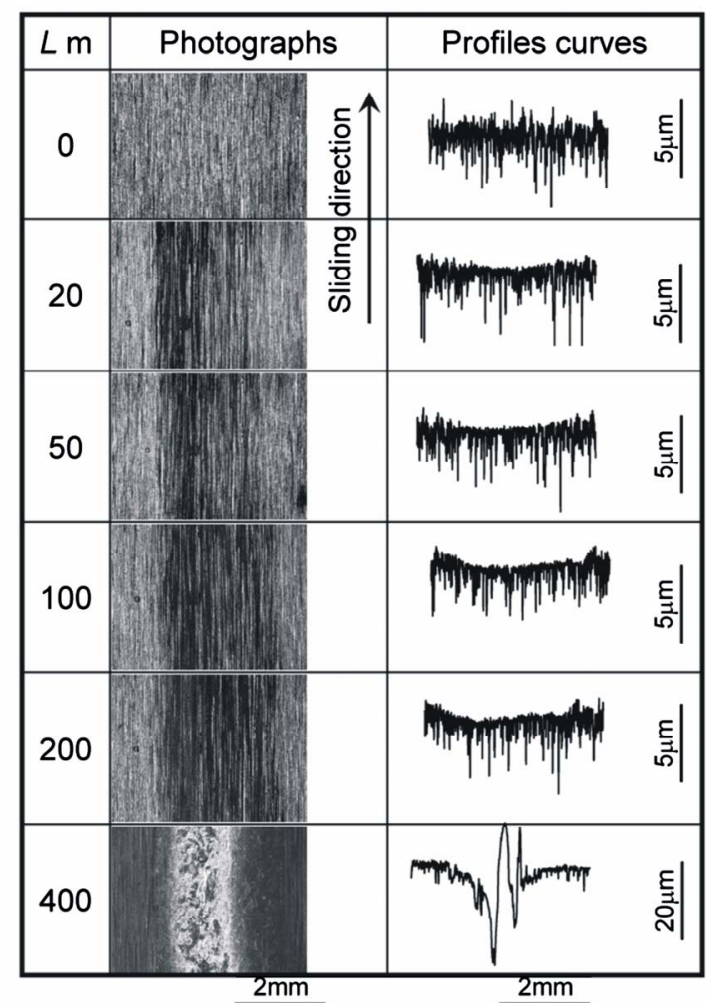

Figure 4. Surface micrographs and profile curves of D3G specimen.

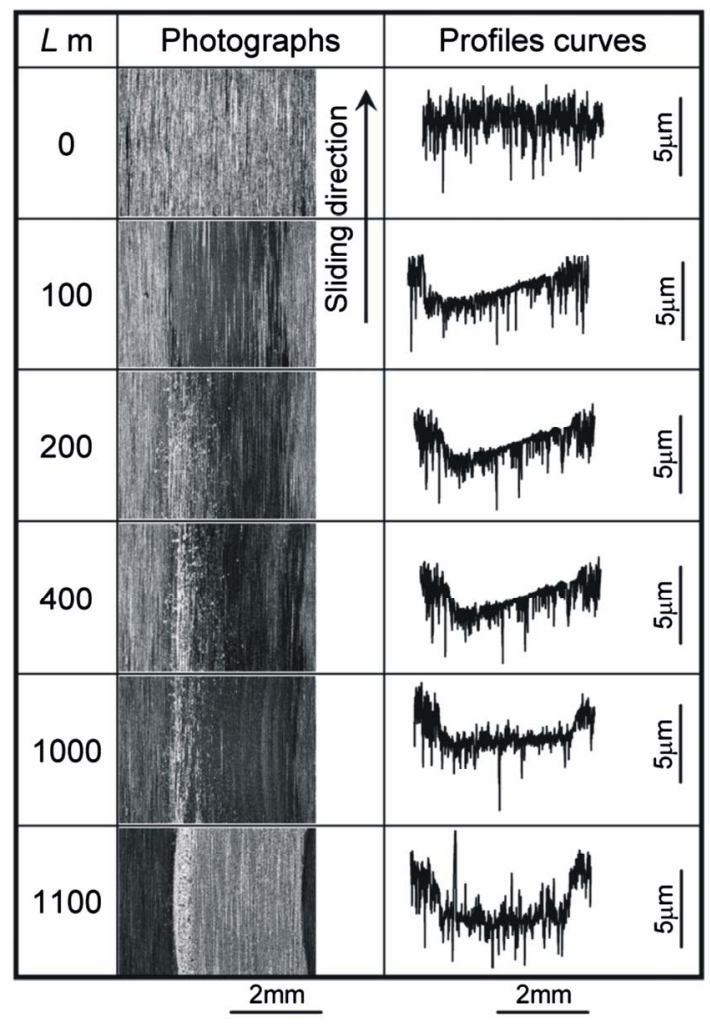

Figure 5. Surface micrographs and profile curves of ND3G specimen. removal of major portion of DLC coatings was observed in the ND3G specimens. The changes in surface micrographs and profiles curves of D10G specimens were shown in Figure 6. It is evident from the profile curves and micrographs like other DLC coated specimens, initially the wear process was mild up to $400 \mathrm{~m}$ of sliding distance and beyond which there was gradual removal of DLC coatings in form of wear debris. It could also be noticed from the depth profile curve at $5400 \mathrm{~m}$; the DLC coating was almost removed and the "blackish appearance" could be accumulation of wear debris during the sliding process. The D10G specimen ultimately failed at $5900 \mathrm{~m}$ of sliding distance. Figure 7 shows the surface micrographs and profile curves of ND10G specimens. The wear process of ND10G specimen was very much analogous to that of D10G specimen. However the eventual failure of ND10G specimen was noticed at $4000 \mathrm{~m}$ of sliding distance.

\subsection{Wear Mechanism}

The wear mechanism of the DLC specimens observed is essentially a gentle polishing during the initial stages of wear process. The surface asperities of DLC specimens were smoothly polished during the beginning stages of the sliding test which could be well noticed from the profiles curves of the DLC specimens shown in (Figures 4-

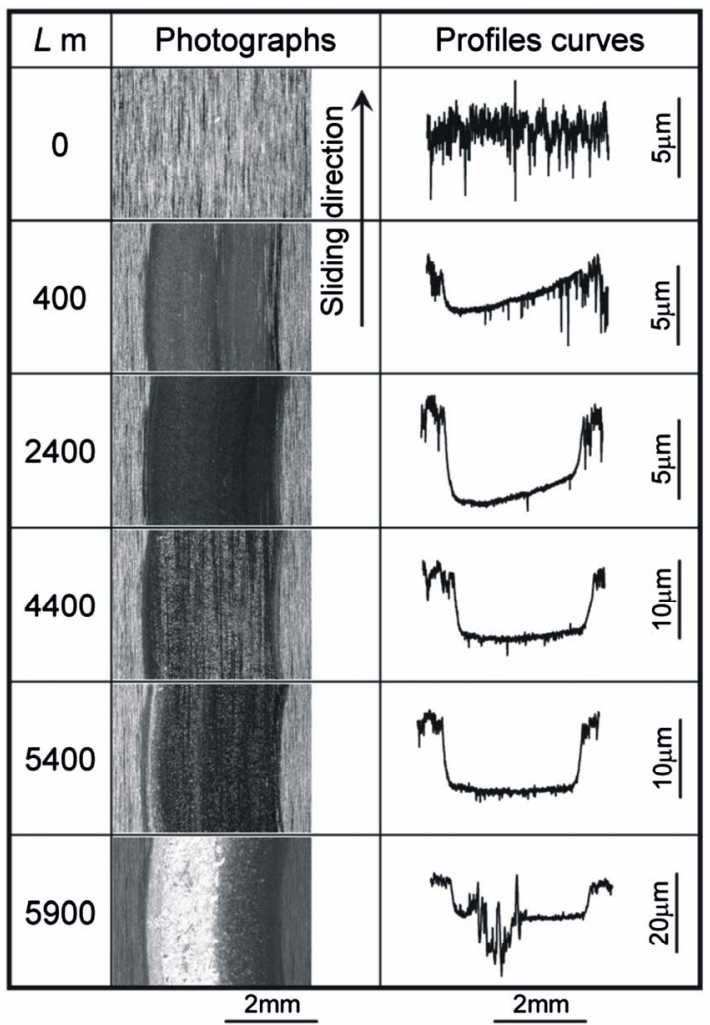

Figure 6. Surface micrographs and profile curves of D10G specimen. 


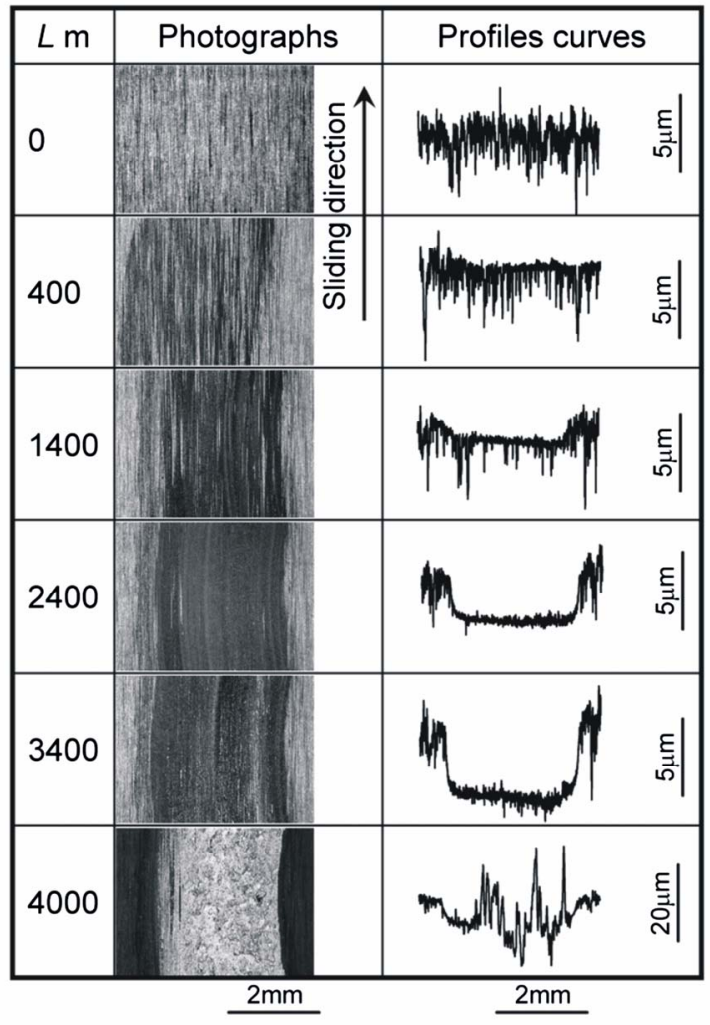

Figure 7. Surface micrographs and profile curves of ND10G specimen.

7). The mild wear process was observed until $50 \mathrm{~m}$ of sliding in $3 \mu \mathrm{m}$ thick DLC coated specimens and up to $400 \mathrm{~m}$ sliding in $10 \mu \mathrm{m}$ thick DLC coated specimens. The polishing of asperities resulted in formation of shallow scratches in between the polished surface which could be seen from optical micrographs of $3 \mu \mathrm{m}$ and 10 $\mu \mathrm{m}$ thick DLC coated specimens taken during the gradual wear stage of the test (Figure 8). Further wear of DLC coatings resulted in the formation of wear debris which got accumulated in those scratches. The formation of such types of scratches and accumulation of wear debris during the sliding contact test of DLC coatings in vacuum corroborates with the findings reported earlier [6]. Also it was observed there were no signs of hazardous wear such as flake formation or delamination of the DLC coatings. During the repeated sliding process; the DLC coatings got worn out gradually and the wear debris got accumulated in the scratches. As the sliding distance increased the wear debris accumulated in the scratches got churned between the sliding parts and were deposited in the wear scar developed in the sliding process. The wear debris deposited on the scar of sliding surface tends to lubricate the sliding surfaces which resulted in the increased wear lives of the sliding parts. This mode of wear debris accumulation in the scratches and scars during the sliding wear of DLC coatings was frequently observed [11-13].
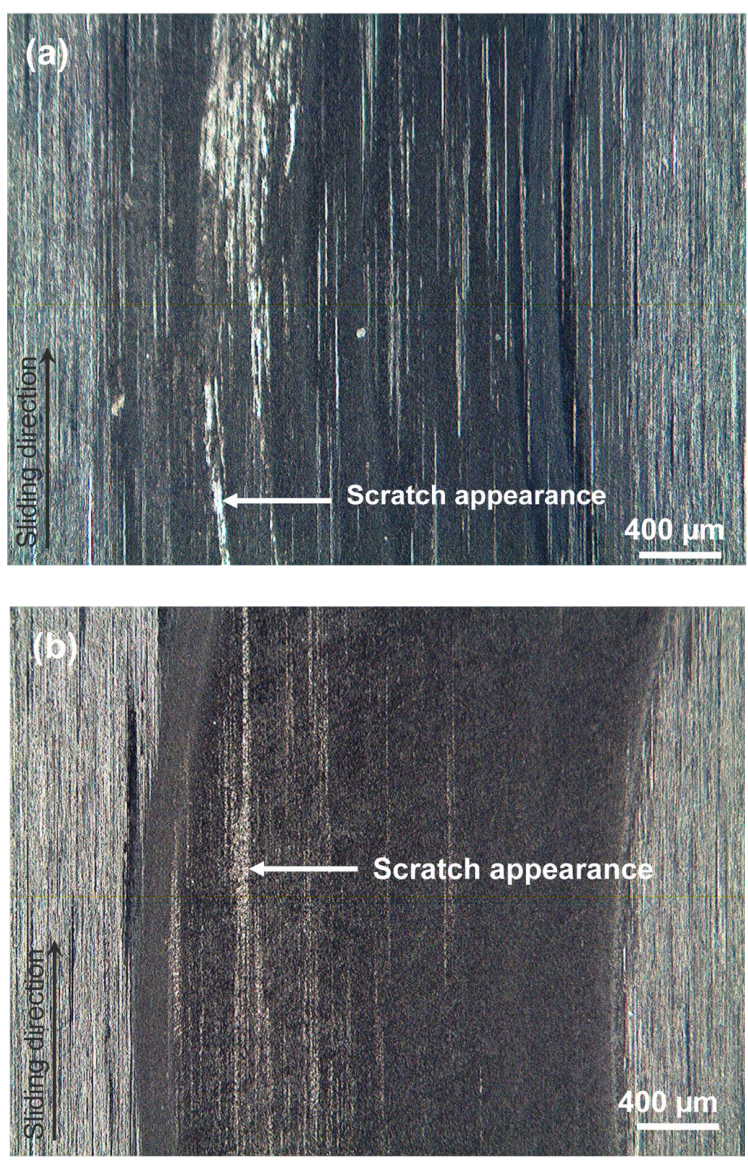

Figure 8. Optical micrographs showing scratches on disk surface of (a) D3G at $L=100 \mathrm{~m}$ and (b) D10G at $L=3400$ m.

The wear mechanism observed in the study could be summarized as; gentle polishing of asperities in the initial stages of sliding test. Once the asperities were polished, the DLC coatings started to worn out gradually during the sliding process. During this stage scratches were developed and were filled up with wear debris formed in the process. Due to repeated sliding process wear scars were also formed on the worn out surface of disk specimen. After longer sliding distances the DLC coating layer appeared to have damaged which eventually worn out by the continuous rubbing of sliding parts.

\section{Conclusions}

The friction and wear behavior of DLC coatings of thickness $3 \mu \mathrm{m}$ and above deposited by Plasma CVD process on stainless steel specimens were investigated in vacuum under sliding contact condition. The results of the study could be summarized as follows:

The friction coefficient of DLC coated specimens was found to be in the range of $0.1-0.35$ for the selected test conditions. The wear resistance of the DLC coating in- 
creased with the thickness of coatings with $10 \mu \mathrm{m}$ thick coatings showing longer wear life. The wear amount of 3 $\mu \mathrm{m}$ thick DLC coated specimen was same up to a sliding distance of $50 \mathrm{~m}$ where as for $10 \mu \mathrm{m}$ thick DLC coated specimens the wear amount was same until $400 \mathrm{~m}$, beyond which varied differently for different specimens. The wear mechanism observed in the study was mainly mild polishing of asperities in the initial stages of sliding test. There were no signs of delamination or flake formation and wear of coating seemed to be an ordered sequence of polishing of asperity peaks, scratch formation, gradual wear of coatings, wear debris formation/accumulation of wear debris in scratches, churning/shearing of wear debris during the repeated sliding process, deposition of wear debris in the wear scar from the repeated sliding process which resulted in the extended wear lives of the DLC coated specimens.

\section{Acknowledgements}

M.Ananth Kumar thanks The Japanese Ministry of Education, Culture, Sports, Science and Technology, Japan (MEXT) for the award of Monbukagakusho scholarship. The authors also thank SHINKO SEIKI CO., LTD. for providing the DLC coatings.

\section{REFERENCES}

[1] S. V. Hainsworth and N. J. Uhure, "Diamond Like Carbon Coatings for Tribology: Production Techniques, Characterization Methods and Applications," International Materials Reviews, Vol. 52, No. 3, 2007, pp. 153-174. doi:10.1179/174328007X160272

[2] J. Robertson, "Diamond-Like Amorphous Carbon," Materials Science and Engineering, Vol. 37, No. 4-6, 2002, pp. 129-281. doi:10.1016/S0927-796X(02)00005-0

[3] A. Grill and V. Patel, "Tribological Properties of Diamond-Like Carbon and Related Materials," Diamond and Related Materials, Vol. 2, No. 5-7, 1993, pp. 597-605. doi:10.1016/0925-9635(93)90190-D

[4] H. I. Kim, J. R. Lince, O. L. Erylimaz and A. Erdemir,
"Environmental Effects on the Friction of Hydrogenated DLC Films," Tribology Letters, Vol. 21, No. 1, 2006, pp. 51-56. doi:10.1007/s11249-005-9008-1

[5] C. Donnet, T. L. Monge, L. Ponsonnet, M. Belin, A. Grill, V. Patel and C. Jahnes, "The Respective Role of Oxygen and Water Vapor on the Tribology of Hydrogenated Diamond-Like Carbon Coatings," Tribology Letters, Vol. 4, No. 3-4, 1998, pp. 259-265. doi:10.1023/A:1019140213257

[6] S. Fredrik, A. K. Rudolphi and E. Wallen, "The Influence of Surface Roughness on Friction and Wear of Machine Element Coatings," Wear, Vol. 254, No. 11, 2003, pp. 1092-1098. doi:10.1016/S0043-1648(03)00341-7

[7] A. Matthews, A. Leyland, K. Holmberg and H. Ronkainen, "Design Aspects of Advanced Tribological Surface Coatings," Surface and Coatings Technology, Vol. 100-101, 1998, pp. 1-6. doi:10.1016/S0257-8972(97)00578-1

[8] F. Qin, Y. K. Chou, D. Nolen and R. G. Thompson, "Coating Thickness Effects on Diamond Coated Cutting Tools," Surface and Coatings Technology, Vol. 204, No. 6-7, 2009, pp. 1056-1060. doi:10.1016/j.surfcoat.2009.06.011

[9] A. Dorner, C. Schurer, G. Reisel, G. Irmer, O. Seidel and E. Muller, "Diamond-Like Carbon-Coated Ti6A14V: Influence of the Coating Thickness on the Structure and Abrasive Wear Resistance," Wear, Vol. 249, No. 5-6, 2001, pp. 489-497. doi:10.1016/S0043-1648(01)00587-7

[10] B. Podgornik, J. Vizintin, H. Ronkainen and K. Holmberg, "Friction and Wear Properties of DLC-Coated Plasma Nitrided Steel in Unidirectional and Reciprocating Sliding," Thin Solid Films, Vol. 377-378, 2000, pp. 254-260. doi:10.1016/S0040-6090(00)01302-X

[11] I. L. Singer, "Mechanics and Chemistry of Solids in Sliding Contact," Langmuir, Vol. 12, 1996, pp. 4486-4491.

[12] I. L. Singer, "How Third-Body Processes Affect Friction and Wear," MRS Bulletin, Vol. 23, No. 6, 1998, pp. 3740.

[13] Y. Liu, A. Erdemir and E. I. Meletis, "A Study of the Wear Mechanism of Diamond-Like Carbon Films," Surface and Coatings Technology, Vol. 82, No. 1-2, 1996, pp. 48-56. doi:10.1016/0257-8972(95)02623-1. 